\title{
Reflexões sobre os efeitos da transnacionalização de currículos e da colonialidade do saber/poder em cooperações internacionais: foco na educação em ciências
}

\author{
Reflections on the effects of transnationalisation of curricula \\ and the coloniality of knowledge/power in international \\ cooperation: focus on science education
}

Suzani Cassiani ${ }^{1}$

\begin{abstract}
Resumo: O Timor-Leste, desde sua independência em 2002, conta com várias cooperações educacionais. Por mais de uma década o Brasil enviou anualmente 50 professores para atuarem na formação de professores em serviço. Porém, ao coordenar esse programa, nos perguntamos até que ponto essas ações poderiam causar efeitos da transnacionalização de currículos, impondo formas de colonialidade do saber/poder. Para tanto, analisamos algumas condições de produção desses discursos em documentos oficiais e em um livro didático elaborado pela cooperação portuguesa. Apontamos que, se por um lado as cooperações internacionais travaram um monólogo eurocêntrico, verticalizado, no qual os saberes locais são silenciados, por outro pode proporcionar o contato com importantes conhecimentos que contribuem na educação para a cidadania e para a consolidação da paz. Esperamos que essas reflexões, no campo da educação em ciências, possam ser propositivas e contribuir com ambos os países, nesse movimento de cooperação educacional sul-sul.
\end{abstract}

Palavras-chave: Colonialidade. Transnacionalizaçao. Currículo. Timor-Leste. Educação em ciências.

\begin{abstract}
Timor-Leste has had several educational co-operation since its independence in 2002. For more than a decade, every year, Brazil has sent 50 Brazilian teachers to work in teacher education. However, in coordinating this program, we wonder how far these actions can affect the transnationalization of curricula, imposing forms of coloniality of knowledge and power? Therefore, we analysed some conditions of production of these discourses, in official documents and in a textbook, written from a Portuguese cooperation. We point out that, if on the one hand, international cooperation often ends up in a vertically centralized Eurocentric monologue, in which local knowledge is silenced, on the other hand it can provide the important knowledge that can contribute to an education for citizenship and to the consolidation for peace. We hope that these reflections in science education can be purposeful and contribute to both countries in this South-South educational cooperation movement.
\end{abstract}

Keywords: Coloniality. Transnationalization. Curriculum. East Timor. Science education.

\footnotetext{
${ }^{1}$ Universidade Federal de Santa Catarina (UFSC), Centro de Ciências da Educação, Departamento de Metodologia de Ensino, Florianópolis, SC, Brasil. Orcid: <https://orcid.org/0000-0001-8824-9342>. E-mail: <suzani.cassiani@ufsc.br>.
} 


\section{Introdução}

O Brasil tem realizado cooperações técnicas com o Timor Leste (TL) desde a época em que este país logrou sua independência em 2002. Em 2004, iniciou-se efetivamente uma cooperação educacional através do Programa de Qualificação de Docentes de Ensino de Língua Portuguesa (PQLP), financiado pela Coordenação de Aperfeiçoamento de Pessoal de Nível Supeior (CAPES), o qual objetivava o envio de 50 professores brasileiros por ano, contribuindo na formação de docentes em Timor Leste.

Minha história com o Timor-Leste iniciou-se quando a Universidade Federal de Santa Catarina (UFSC) passou a coordenar o PQLP, em 2009. A tarefa da comissão gestora, designada pela UFSC, foi a de elaborar editais, selecionar cooperantes, preparar interações pré-partidas, acompanhar o trabalho desenvolvido, orientar no que fosse possível, bem como avaliar o trabalho desses brasileiros durante o tempo em que lá permaneciam. Além disso, o grupo gestor realizava articulações políticas com autoridades timorenses, sempre com o objetivo de pensar na formação de professores e no ensino de língua portuguesa.

Nesse contexto, uma série de questões foram levantadas, as quais têm permeado a trajetória do nosso grupo de pesquisa ${ }^{2}$, a saber: (1) como ensinar ciências em língua portuguesa a não falantes ou pouco falantes de português, futuros professores ou docentes em serviço, os quais necessitam de formações numa língua que não têm domínio?; (2) Quais os efeitos da transnacionalização de currículos, já que uma transferência de saberes é pressuposta? Como atuar em parceria com o Timor, favorecendo o diálogo de saberes e a emancipação do povo timorense, e não a criação de dependência? Quais os desafios para ambos, brasileiros e timorenses, sobre quais ciências ensinar num país pós-conflito?

Ao longo do trabalho, o grupo concluiu que as cooperações internacionais possuíam tendências que envolviam assistencialismos, ensino fora da realidade timorense, produzindo novas formas de colonialismos, como a valorização exacerbada de uma ciência eurocêntrica, branca e masculina (CASSIANI et al., 2016). Esse movimento de transnacionalização curricular começou a ficar evidente, tanto em práticas de cooperantes brasileiros, quanto em práticas de outras cooperações, refletidas como um movimento interfronteiras dos currículos educacionais, dos países em cooperação técnica com Timor-Leste.

Essas percepções levaram o grupo a repensar a necessidade de aprofundamentos sobre as formas de participação do Brasil, que poderiam estar vinculadas superficialmente às políticas de ajuda externa em educação, e que precisavam ser pensadas criticamente. Enfim, as pesquisas indicaram que estas cooperações educacionais precisavam ser repensadas em suas ações, sendo necessária a proposição de novos caminhos nesses processos.

Tais reflexões nos remeteram a problemas mais amplos, como a globalização e suas consequências, aprofundamentos de noções teóricas que remetiam a transnacionalização do currículo e efeitos de colonialidade do saber/poder, ao pensar em uma educação assistencialista. Portanto, nesse artigo, considero essencial explicitar os sentidos relacionados a estas

\footnotetext{
${ }^{2}$ Discursos da Ciência e da Tecnologia na Educação. Disponível em: <http://dicite.paginas.ufsc.br/>. Acesso em: 31 jan. 2018. 
noções, a partir do enfoque de alguns autores que se debruçam a estudá-las, tomando como base das análises discursos que circulam atualmente em materiais didáticos daquele país. (CASTRO-GÓMEZ; GROSFOGUEL, 2007; MIGNOLO, 2003; ORLANDI, 2009; QUIJANO, 2000; SANTOS, 2010; SANTOS; MENESES, 2013).

Nesse sentido visa-se compreender os discursos que circulam na educação científica timorense, tendo como foco os efeitos da transnacionalização da educação e da colonialidade do saber/poder, e o quanto os aspectos de uma educação assistencialista no processo podem estar presentes. Para tanto, serão analisadas algumas condições de produção desses discursos em documentos oficiais e num determinado livro didático em uso no Timor-Leste, elaborado pela cooperação portuguesa. Espero que essas reflexões na educação em ciências possam ser propositivas e contribuir com os dois países nesse movimento de cooperação educacional.

\section{Referenciais teórico-metodológicos}

Entendemos que os conceitos de transnacionalização e da colonialidade do saber/ poder estão interligados e consequentes, não acontecendo somente em cooperações internacionais. Essas diferenças acontecem também no Brasil com grande dimensão e, portanto, com desigualdades sociais, pensando nas regiões Sul e Sudeste as quais podem impor aos estados do Norte e Nordeste uma relação de poder.

Paulo Freire (FREIRE, 1985, p. 80) já criticava o assistencialismo educativo quando apontava que:

As relações entre o educador verbalista, dissertador de um 'conhecimento' memorizado e não buscado ou trabalhado duramente, e seus educandos, constitui uma espécie de assistencialismo educativo. Assistencialismo em que as palavras ocas são como as 'dádivas', características das formas assistencialistas de domínio social.

Ao se referir a situação de ensino numa sala de aula, o autor nos remete a necessidade de ruptura, promovendo um ensino no qual deve ser problematizado e compreendido pela intercomunicação, pelo diálogo.

Ao analisar as ações da cooperação brasileira junto ao PQLP, Pereira (2014, p. 153) identificou o assistencialismo educativo, quando os cooperantes apontaram alguns problemas vivenciados desde 2005 “a gente está colonizando de novo. Está colonizando um povo livre, na verdade" ou "[...] talvez uma forma de assistencialismo é você colocar a sua forma de pensar sem considerar a realidade" (PEREIRA, 2014, p. 155). Segundo a autora, isso se deu porque os professores timorenses não haviam sido incorporados no processo da construção do currículo.

Devido ao fato de que a palavra missão é utilizada pela CAPES, além de organismos internacionais, isso atraiu alguns professores que construíram uma ideia de cooperação num sentido religioso, em que era preciso salvar aquele povo. É interessante observar essas inserções numa cooperação bilateral com pretensão de sentido laico.

Nesse caminho, consideramos que o sentido de ajuda realizado nessa situação emergencial poderia levar a um silenciamento da cultura local e, por sua vez, à subalternidade, remetendo 
à inferioridade, dependência, e subordinação. Freire (1978, p. 20) já ressaltava essas questões quando realizou um trabalho na área da educação de Guiné Bissau:

Fazia-se necessário que os estudantes guineenses estudassem, prioritariamente, sua geografia e não a de Portugal; que estudassem seus braços de mar, seu clima e não o Rio Tejo. Era preciso que os estudantes guineenses estudassem, prioritariamente, sua história, a história da resistência de seu povo ao invasor, a da luta por sua libertação que lhe devolveu o direito de fazer sua história, e não a história dos reis de Portugal e das intrigas da Corte.

Nessa citação, o autor exemplifica o que poderia ser ensinado a um país que logrou sua independência em 1973. Ao não ter uma história sistematizada, o que era ensinado nas escolas era relativo à história de Portugal. Sabemos que esse é um dos problemas relacionados aos efeitos de colonialidade do saber/poder, os quais acabam fortalecendo uma história e saberes que não são locais (QUIJANO, 2000; SANTOS; MENESES, 2013).

Orlandi (2009) também alertou sobre uma forma de colonialidade do saber na academia, quando a língua inglesa impera como a língua da ciência, ressaltando a importância de parafrasearmos autores europeus para que nossos trabalhos sejam aceitos em revistas nacionais e internacionais. Como num efeito de etnocentrismo invertido, esse sentido aparece não somente na produção da ciência, mas também em processos de consumo de produtos, de comportamento, na educação, ideias que circulam que "se é estadunidense ou europeu é melhor". Em contraponto, surge a ideia de que se é da cultura local deve ser menos valorizado.

Para entendermos os efeitos do etnocentrismo invertido, é importante falar em globalização hegemônica. Segundo Santos (2010), essa possui a capacidade de desqualificar formas de política, formas de economia e conhecimentos rivais como práticas locais, portanto, inadequadas. Em consonância, Quijano (2000) afirma que a colonialidade do poder é uma nova forma de colonização muito mais subjetiva, em que os povos colonizados aprendem a cultura dos dominadores para a reprodução dessa dominação no campo material, tecnológico e subjetivo. A colonialidade do saber/poder produz modelos que vem dos países de capitalismo central e que produz diferentes formas de desigualdade, seja de gênero, etnia, sexualidade, etc. A dominação é naturalizada como o imaginário cultural europeu, como a única forma, eliminando e substituindo os conhecimentos ancestrais dos nativos por conhecimentos que se embutem de pretensas verdades, universais e científicas.

Nesse caminho, considero que a transnacionalização da educação possa ser uma das formas modernas desses processos. Autores como Ortiz (1994) e Dale (2004) situam a transnacionalização como transferências de saberes e ideias pensadas/planejadas em outras situações e nações, tanto para aquelas em desenvolvimento quanto para as que estão ainda em fase de estruturação. Dale (2004) não concorda com o pensamento comum de que a homogeneização do currículo acontece de forma neutra, devido ao compartilhamento de valores de modernidade e progresso entre os países, mas sim de tentativas supranacionais de manutenção das estruturas capitalistas, onde os países recebem moldes e padrões de modernidade e progresso necessários para sua pertença na comunidade internacional. 
Mignolo (2003, p. 36) também nos ajuda a entender que "as diferenças coloniais significam a classificação do planeta do imaginário colonial/moderno praticada pela colonialidade do poder, uma energia e um maquinário que transformam diferenças em valores”. Assim, é importante se ter em conta que esta dominação não se dá unicamente no sentido (asséptico) da Europa ao Timor-Leste, mas na forma de um efeito simbólico, repleto de contaminações simbólicas (e por isso não asséptico) em que o Brasil atua como intermediário nestas relações, ao incorporar traços de um país independente. Desta maneira, uma 'despretensiosa' aproximação mais do que fornecer elemento de libertação/emancipação, pode vir a acorrentar os povos ainda mais à sua condição de pós-colonizado, ou seja, à condição de um país que, embora possua certa independência política, não se vê livre dos seus laços culturais subalternos ao antigo ou novo 'protetor' ou 'tutor' (SOUZA; ALVES, 2008).

Carter $(2004,2006)$ também contribui com esses estudos para pensar de uma forma diferente, sobre os aspectos da diversidade cultural na educação científica. Ela sugere que análises pós-coloniais são importantes, pois nos fazem pensar nas condições materiais e culturais, nas quais a educação em ciências é produzida, circulada, interpretada e divulgada.

Além disso, os estudos sociais da Ciência e Tecnologia associado ao funcionamento discursivo, tomando como base Teorias do discurso (ORLANDI, 1996; PÊCHEUX, 1993) têm nos dado suporte para entender as relações que envolvem Ciência, Tecnologia e Sociedade. Esses aportes nos levam a questionar de que forma essas relações são colocadas em funcionamento no contexto atual e de que forma podemos promover um trabalho pedagógico no ensino de ciências que caminhe para se pensar, propor, questionar possíveis implicações sociais das ciências e das tecnologias (CASSIANI; LINSINGEN, 2011).

Ao incorporar discussões dessas dimensões, muitas vezes silenciadas em debates da área da Educação em Ciências e associadas à compreensão dos processos que passou o Timor-Leste, percebemos a importância de uma educação mais crítica que possa contribuir para o desenvolvimento e a promoção da paz, segurança e estabilidade no país (FREIRE; LOPES, 2014).

$\mathrm{Na}$ abordagem metodológica, utilizaremos a Análise de Discurso da linha francesa (AD). Uma das noções mais importantes da $\mathrm{AD}$ são as condições de produção de sentidos (ORLANDI, 1996) que envolvem a compreensão de situações imediatas e amplas no que se refere ao funcionamento de texto dentro dos discursos. Para compreender essas condições de produção dos discursos sobre ciências que circulam na educação timorense, enfocaremos primeiramente documentos oficiais como o "Plano Curricular do $3^{\circ}$ Ciclo do Ensino Básico" e sua "Estratégia de Implementação", que tem como uma de suas metas a implantação e avaliação do currículo, produzido pela cooperação portuguesa.

Num segundo momento, apresentamos algumas análises de um manual didático do ensino fundamental. Os critérios na escolha desse material e, especificamente deste ano, teve como base sua atual circulação em escolas timorenses. Também se levou em conta o conteúdo programático do livro, que envolve uma ligação com as pesquisas dos grupos Discursos da Ciência e da Tecnologia na Educação (DICITE), da UFSC, e Grupo de Estudos em Ensino de Ciências e Tecnologias (GEECITE) da Faculdade de Educação, Artes e Humanidades da Universidade Nacional Timor Lorosa'e (UNTL), focadas nas relações Ciência-Tecnologia-Sociedade (CTS) e na educação CTS. 


\section{Condições de produção de sentidos sobre o currículo dos últimos anos do ensino fundamental}

Em 2009, o Ministério da Educação de Timor-Leste solicitou o apoio da UNICEF e de Portugal, especificamente o Instituto Português de Apoio ao Desenvolvimento, que delegou à Universidade do Minho (UM) a tarefa de reestruturar o currículo do Ensino Fundamental ${ }^{3}$ no país. No documento elaborado pela equipe da UM, é esclarecido que se visava apoiar a criação de um currículo nessas perspectivas:

(i) mais ajustado ao contexto social e cultural de Timor-Leste e aos objectivos de desenvolvimento do sistema educativo timorense; (ii) mais coerente com os padrões internacionais e com os desafios que hoje se colocam aos sistemas educativos, em geral; (iii) mais articulado com os currículos dos ciclos de ensino que o antecedem $\left(1^{\circ}\right.$ e $2^{\circ}$ Ciclos do Ensino Básico); (iv) mais adequado aos alunos a que se destina. (PACHECO et al., 2009, p. 5, grifos nossos).

Podemos observar que nesse excerto, já há indícios sobre preocupações com o contexto timorense, primando por uma adequação no ensino. Por outro lado, a (in)coerência com os padrões internacionais, defendida no documento, pode demonstrar uma contradição, quanto pensa numa padronização forçada que algumas avaliações internacionais proporcionam, remetendo à globalização, ao neoliberalismo e à dependência dos países em desenvolvimento ${ }^{4}$.

Nesse mesmo documento, há o plano curricular, no qual foram apresentadas, descritas e caracterizadas três áreas de desenvolvimento: (1) Linguística; (2) Científica: Matemática, Ciências Físico-Naturais, História e Geografia; (3) Pessoal e social. A área relacionada ao ensino de ciências traz a seguinte caracterização:

A área de desenvolvimento científico, tomando como objecto os contributos de diferentes disciplinas académicas, transpostos para o campo escolar, visa dotar os alunos de saberes culturais, científicos e tecnológicos que os tornem aptos a compreender aspectos da realidade e a lidar adequadamente com situações problemáticas que se lhes coloquem enquanto cidadãos. (PACHECO et al., 2009, p. 39, grifos nossos).

\footnotetext{
${ }^{3}$ Em Timor-Leste, esse nível de ensino é chamado de Pré-Secundário.

${ }^{4}$ Para citar um exemplo, a avaliação realizada pelo Program for International Student Assessment (PISA), proposto pela Organização para a Cooperação e Desenvolvimento Econômico (OCDE), uma organização econômica que avalia o campo da educação sem explicitar seus interesses. No Brasil, que geralmente ocupa os últimos lugares do ranking mundial, o PISA ganhou uma importância grande na mídia, causando um eterno clamor pela melhoria da educação. No entanto, há ainda poucas reflexões sobre a não transparência da linguagem nas provas e as diferentes interpretações, os diferentes contextos que não são levados em conta nos países envolvidos. Portanto, há ênfase em um tipo de conhecimento eurocêntrico. Os rankings estabelecidos pelo PISA são interpretados como confiáveis, ficando evidentes as relações de poder entre os países ditos desenvolvidos que fazem parte da OCDE.
} 
Para fins de contextualização e problematização, a disciplina de Ciências não existia nas escolas de Timor-Leste. Nas últimas séries do ensino fundamental, os professores ensinavam separadamente disciplinas das ciências naturais (Biologia, Física, Geociências, Química). Então, o novo currículo contemplou a introdução dessa nova disciplina que abarcava para si vários campos interdisciplinares do conhecimento. A inserção da disciplina de Ciências ocorreu no $2^{\circ}$ e $3^{\circ}$ ciclos sem o devido envolvimento dos professores, mesmo isso sendo uma das ações privilegiadas pelos documentos.

Nas missões da cooperação brasileira em várias reuniões com dirigentes do Instituto Nacional de Formação de Docentes e Profissionais da Educação, havia sempre a demanda de que os professores não conseguiam ensinar com os conteúdos integrados, solicitando nosso apoio no desenvolvimento de projetos temáticos, conforme propusemos em três escolas.

Por estar num documento específico do Ensino de Ciências, é interessante notar a importância dada aos saberes culturais, além dos científicos e tecnológicos. Porém, ficamos intrigados em analisar os materiais didáticos para tentar perceber essa integração.

Além disso, o documento frisa que:

Como forma de acção privilegia-se uma metodologia participada. Reconhecida em diversas áreas, programas e projectos que envolvem níveis elevados de cooperação, esta metodologia possibilita não só adequar os projectos às características de contextos regionais e locais, como também melhorar o envolvimento das pessoas num processo contínuo que visa clarificar que objectivos a atingir. (PACHECO et al., 2009, p. 67, grifos nossos).

Como já dissemos, apesar do projeto prever uma metodologia participativa, de cooperação e valorização dos contextos, a construção curricular se deu principalmente pelas instituições portuguesas responsáveis, e não teve a devida participação dos professores timorenses.

Ramos e Teles (2012) apontam que o ministro da educação de Timor-Leste tinha considerado que a estruturação do plano curricular deveria ser feitos em articulação com professores timorenses, bem como a elaboração dos programas das disciplinas, dos manuais para os alunos e dos guias para os professores.

O próprio coordenador da parte da Universidade do Minho, em entrevista em 2011, já salientava possíveis dificuldades na implementação do projeto, quando disse que seria mesmo difícil levar as orientações para o terreno e fazer com que aquilo que os professores ensinam e aquilo que os alunos aprendem nas escolas tenham como referência os documentos que foram elaborados 5 .

\footnotetext{
${ }^{5}$ Prof. Dr. Rui Castro em entrevista publicada no site da Universidade do Minho em 2011: "Quando nós acabamos o trabalho, aquilo que eu tive ocasião de dizer aos responsáveis políticos timorenses foi que, apesar de tudo, o que tinha sido feito fora a parte mais fácil, ou seja, conceber orientações de política curricular, desenhar um plano de estudos, elaborar programas e guias para os professores trabalharem. Isto foi, apesar de tudo, o mais fácil. Difícil mesmo é levar estas orientações para o terreno e fazer com que aquilo que os professores ensinam e aquilo que os alunos aprendem nas escolas tenha como referência os documentos que elaborámos". (CASSIANI; BARBOSA, 2015, p. 163).
} 
Nesse cenário de complexidade multicultural e plurilíngue que é o Timor-Leste, outros problemas emergiram. Por exemplo, a dificuldade com a Língua Portuguesa e a implantação de um novo currículo exógeno não produzido pelos professores timorenses.

Nesse sentido, veremos nas análises do material didático elaborado para o Timor-Leste, efeitos dessa globalização hegemônica e da colonialidade do saber/poder, através da transnacionalização dos currículos, que possui uma perspectiva de reprodução de sentidos ocidentais e descontextualizados. Entendemos que ao explicitarmos esses limites, estaremos avançando em futuras cooperações.

\section{Funcionamento da transnacionalização do currículo}

Nesse tópico, o corpus de análise é o manual didático do $7^{\circ}$ ano, pois consideramos que os manuais em geral são materializações do currículo e cenários de muitas contradições e desafios. Ao mesmo tempo que são importantes para o ensino, também são recursos políticos e ideológicos poderosos, terrenos de disputa entre as editoras, já que envolvem muitos interesses econômicos.

Como já dissemos, o manual (COSTA; RODRIGUES; DIAS, 2011) em questão foi impresso pela Porto Editora (Portugal) e possui 176 páginas. Logo na capa, aparece a inscrição "Livro aprovado pelo Ministério da educação de Timor-Leste", mas não se esclarece a autoria. Os nomes dos autores, em letras pequeninas, aparecem somente na contracapa, como "criação intelectual". São autores portugueses de dois diferentes manuais didáticos de Ciências, utilizados em escolas portuguesas. Segundo relatos orais, os professores timorenses quase não participaram da elaboração dos livros didáticos, como defendia os documentos oficiais na produção do currículo pelo convênio da Universidade do Minho.

Partindo do pressuposto da adequação dos conteúdos, chamou-nos a atenção o fato do livro querer abarcar tantas áreas, como Astronomia; Geociências; Materiais e Energia; Movimentos e forças; num primeiro bloco (da página 6 a 109). No segundo bloco, a ênfase é maior em Biologia, iniciando com Ecologia e defesa da biodiversidade; Organismo humano; Sustentabilidade e Evolução (páginas 112 a 176). De um modo geral, há grande superficialidade dos conteúdos, pouca integração entre temas e capítulos e quase nenhuma valorização de experiência dos alunos. As Referências bibliográficas, as citações ou as sugestões de leitura também estão ausentes. É como se todos esses conceitos não tivessem história, remetendo a sentidos de neutralidade, de verdade absoluta e incontestável.

É interessante ressaltar que essas áreas propostas no livro - Geociências, Química, Física e Biologia - tradicionalmente são fragmentadas nos diferentes anos no Brasil. No entanto, apesar de ser uma tentativa louvável, pode ser de difícil concretização, pois a fragmentação dos conteúdos nas diferentes séries do ensino de ciências está nas bases epistemológicas da própria construção histórica da ciência, e a interdisciplinaridade é algo bastante rara nos bancos escolares. Para o contexto educacional timorense, que recém começa a reverter a situação em que mais de $80 \%$ dos professores não têm formação acadêmica e poucos estudaram em universidades, há de se analisar a elaboração de manuais distante de sua atuação, principalmente em relação à construção de conhecimentos naquele particular âmbito plurilíngue, em que muitos não falam Português. O Tétum falado em quase $100 \%$ da população timorense, nessa altura, poderia dialogar com o Português nesses materiais, os quais poderiam ser bilíngues. Muitas vezes o 
que se percebe é uma competição, mas consideramos que as duas línguas devem ser assumidas como patrimônio do Timor-Leste.

Já havíamos percebido problemas nos materiais produzidos pelos professores brasileiros em anos anteriores, em que falas descontextualizadas constavam no material produzido para o Timor-Leste. Porém, aqueles materiais foram produzidos numa situação emergencial, na qual não havia materiais disponíveis. Ainda assim, apesar da possível inexperiência em escrever livros didáticos, por parte dos professores brasileiros, eles moravam no Timor-Leste, conviviam com os professores de Timor-Leste e conheciam um pouco melhor a realidade timorense. Há de se repensar nessas ações e sair dessas zonas de emergência. (PEREIRA; CASSIANI; LINSINGEN, 2015).

Sabemos que é reduzida a oferta de publicações e recursos didáticos em Língua Portuguesa. É comum jovens timorenses abordarem brasileiros e portugueses, pedindo livros e dicionários em Português, reflexo da quase inexistência de livrarias no país. Segundo Gonçalves (2012), os livros escolares e estratégias pedagógicas utilizadas para a aprendizagem da/em Língua Portuguesa nas escolas têm sido elaborados sem conhecimento das realidades locais e das características do Tétum e com omissão de aspectos importantes das histórias de Timor-Leste, decorrente da muito provável falta de conhecimentos dos estrangeiros sobre o país.

O incentivo e ampliação dos materiais em Língua Tétum, bem como o estudo e a pesquisa de aspectos socioculturais de Timor-Leste é sumamente importante para superar assunções de superioridade linguística/cultural e de colonialidade do saber/poder.

Para compreender o choque de culturas, neste excerto abaixo, trazemos a fala de uma professora timorense da escola básica, na qual é possível perceber a dificuldade nessa transnacionalização de currículos, a qual os timorenses estão sendo submetidos:

[...] podemos relacionar com a realidade que tem. Tanto que, antes, eu pensava: 'onde vamos buscar esse objeto?' E esse objeto podia estar mais perto de nós. Dantes, se falava em telemóvel e não via o telemóvel. Outra coisa, por exemplo, dantes, dizia: 'os alimentos, podemos guardar no frigorífico' [geladeira], mas antes não via o frigorífico, não tinha em Timor. Agora, podemos mostrar a eles [os alunos] o frigorífico, não simplesmente pintar no quadro, mas posso tirar foto e mostrar na sala. (PEREIRA, 2014, p. 176).

Aqui, destacamos a distância dos exemplos que as cooperações internacionais se utilizaram para a elaboração de manuais didáticos. Segundo relato do então Ministro da Educação, João Câncio, em 2011 ainda havia em torno de 85\% de professores sem formação acadêmica. Isso ocorreu quando da independência, em 1999, quem falava Português ou tinha algum diploma universitário tornou-se professor da escola básica:

A qualidade dos professores e a qualidade da formação de professores são problemáticas. Esta situação tem as suas raízes em eventos históricos. No período depois do referendo de 1999, os professores indonésios, particularmente os do $3 .^{\circ}$ ciclo e secundário, deixaram Timor-Leste. Isto deu origem a uma crise de oferta de professores que se tentou resolver através da contratação pela UNMIT de professores locais que possuíam habilitações 
académicas limitadas e pouca ou nenhuma formação ou experiência de ensino. Isto originou problemas de qualidade de ensino que subsistem até hoje. Com o apoio dos parceiros de desenvolvimento, muitos professores têm recebido formação numa variedade de áreas, incluindo o Português, as Ciências e a Matemática, assim como em metodologias de ensino. Este apoio foi delineado para atender às necessidades de formação mais críticas, particularmente as relacionadas com a língua, contudo são necessários mais contributos (TIMOR LESTE, 2011, p. 40).

Nesse sentido, podemos perceber que os livros são muito importantes, pois os professores acabam aprendendo os conteúdos com os livros, já que a formação continuada de professores é feita em tempos pontuais ao longo do ano.

Em nossas análises, destacamos parâmetros que aprofundamos pela Análise do Discurso da linha francesa (PECHEUX, 1993), buscando o entendimento dos efeitos de sentidos sobre colonialidade do saber no texto didático, contribuindo assim para ampliar o entendimento do funcionamento da transnacionalização do currículo. O primeiro deles é a noção de Silêncio. Para a AD francesa, o silêncio pode ter várias formas (ORLANDI, 1995): a incompletude, ou seja, a impossibilidade de dizer tudo; o silêncio da censura; o silêncio do anti-implícito, ou seja, a exposição do que não é dito através do dito. Nessa última forma de silêncio, ressalto que ao trazer exemplos distantes da realidade local, há uma priorização de outras culturas, mesmo que isso não seja feito deliberadamente com má intenção, mas sim pelo simples fato dos estrangeiros não conhecerem o país. Qual seria o efeito de sentido para os professores e estudantes sobre esses silêncios? Qual o efeito desses não ditos?

Abaixo, alguns exemplos desses silenciamentos:

- Na maioria dos capítulos, o manual traz poucas referências ao cotidiano e realidade de Timor-Leste. Somente os capítulos 5 e 7 trazem algo relacionado ao local, voltado às geociências: tipo de rocha, terremotos. Há silêncio sobre agricultura de subsistência com fotos de monoculturas. Por exemplo, não há menção sobre o café orgânico, que é um dos maiores produtos de exportação do país. Exemplos de transportes exógenos, o Tuc Tuc que é de Bali. Imagem de uma fábrica com chaminé para falar de poluição, mas não há fábricas ainda em Timor-Leste. Também podem ser exploradas questões com relevância social e econômica e sobre a pobreza em alguns países, ressaltando como a ciência não é neutra quando se pensa em investimentos globais. São informações importantes para a cidadania, para a melhoria das condições de vida da população. No capítulo 5, cuja abordagem é sobre ecologia, não há exemplos da fauna e flora timorense.

- Silêncios sobre os problemas com a água, como a falta de tratamento e esgoto a céu aberto, naturalizando com imagens de uma Estação de Tratamento. Poderiam, por exemplo, ensinar as ciências para melhorar as condições de vida, diminuindo assim a mortalidade infantil, por exemplo, quando ensinamos que devemos ferver a água para dar de beber às crianças.

- No último capítulo, do manual (seis), são abordados os sistemas do corpo humano. Não sem motivos, o último sistema é o reprodutor, como acontece também em vários livros brasileiros, por tocar num assunto que é tabu, ou seja, a sexualidade. Na imagem do aparelho reprodutor feminino, não há o desenho do clitóris e nem é mencionada a sua função. 
- Falta de abordagens científicas articuladas aos temas locais: ilustrações de experimentos em laboratórios (capítulo três). Ao serem colocadas várias imagens desse tipo, dá-se importância demasiada aos laboratórios como espaços imprescindíveis de aprendizagem. Esse discurso é muito semelhante ao que aconteceu no Brasil com os professores brasileiros, ideia que foi introduzida pelo acordo entre o Ministério da Educação e Cultura do Brasil e a USAID nos anos 1960.

Na Figura 1, pode-se perceber um exemplo de destilação muito comum em Timor-Leste, na elaboração da bebida Tua Sabu, feita a partir da palmeira de nome Tuaca.

Figura 1. Processo de destilação do aguardente de palmeira (bebida típica)
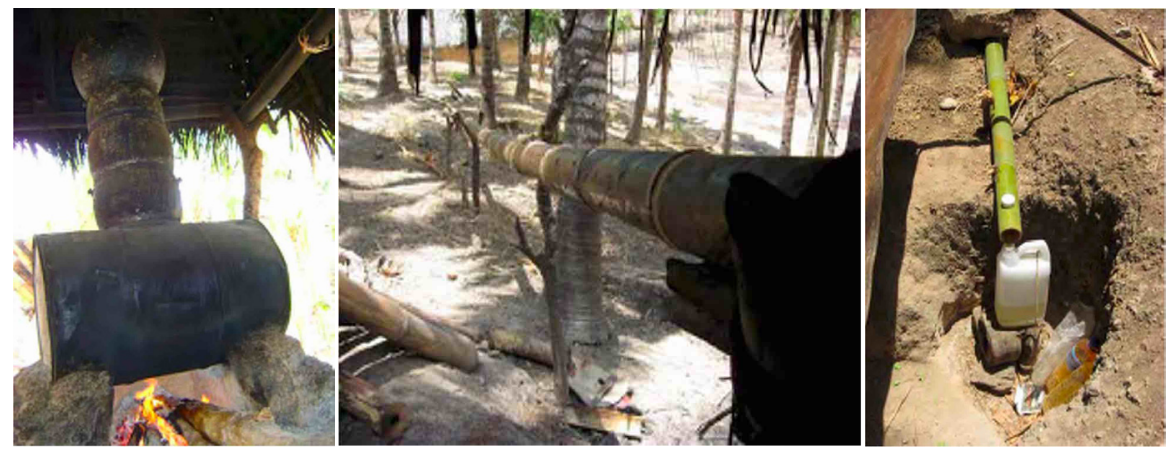

Fonte: Gabrielson (2009).

Em contraponto, e considerando que a figura acima poderia ter sido utilizada como exemplo, na Figura 2 abaixo representada, podemos perceber a distância do cotidiano timorense quando o manual didático se remete à destilação.

Figura 2. Ilustrações sobre demonstrações de tipos de destilação

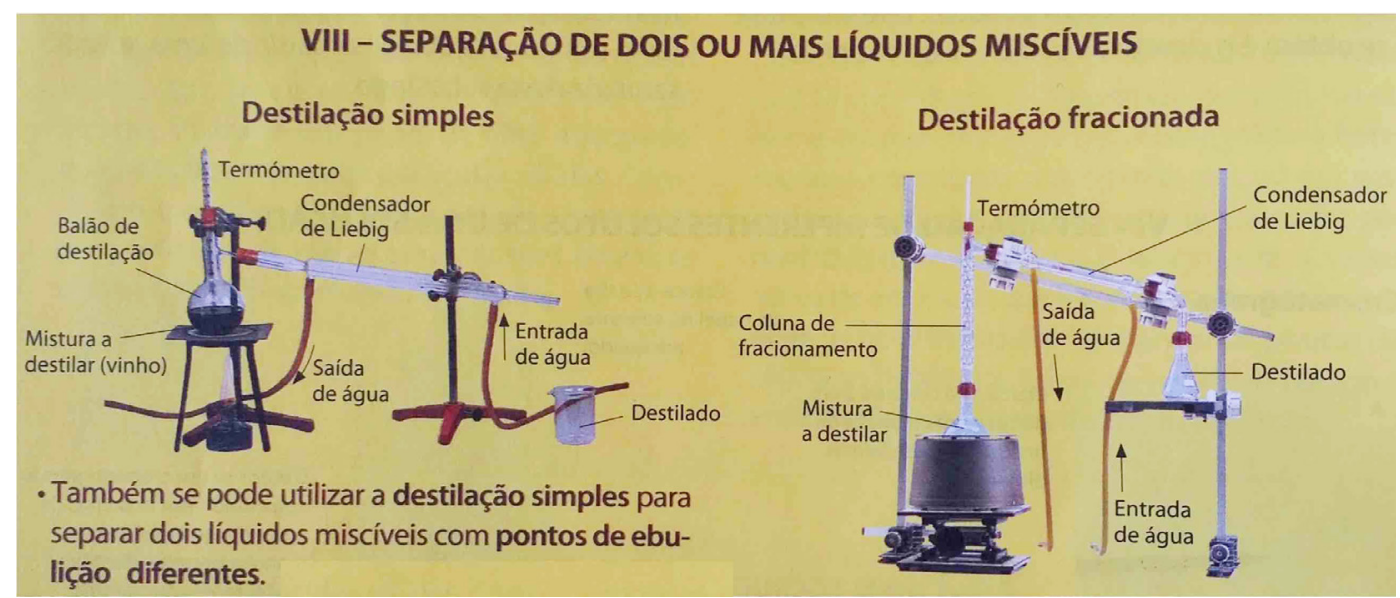

Fonte: Costa, Rodrigues e Dias (2011, p. 68). 
Ou seja, para o mesmo fenômeno, é priorizado a figura de um laboratório local tão raro no país. Consideramos que se trouxermos exemplos mais próximos da realidade, haverá maior chance de aprendizagem sobre os conteúdos científicos. Como não há separação entre forma e conteúdo, ou seja, a forma como se diz influencia na construção de sentidos (PÊCHEUX, 1993), não é difícil afirmar que esse exemplo da destilação poderia ser melhor compreendido com temas locais.

Entender os fenômenos da natureza, explicando-os pelo entorno, pela realidade local, seria muito mais frutífero. Não queremos dizer com isso que os conhecimentos a serem ensinados devam ser somente aqueles aos quais os estudantes estão próximos ou têm e/ou podem visualizar.

A ocidentalização do olhar não seria tão grave se o Timor-Leste não fosse um dos países mais pobres da Ásia, com um dos maiores índices de mortalidade infantil, num cenário onde o ensino de ciências poderia contribuir para o acesso às informações que pudessem evitar a diarreia em recém-nascidos, por exemplo. Enfim, o silenciamento de alguns sentidos promoverá a instauração de outros. Por isso, entendemos que a proposição de conhecimentos mais focados aos problemas poderia melhor contribuir para o país, no sentido de que pudessem refletir e tentar resolver seus próprios problemas, e não problemas importados de sociedades ocidentalizadas. Porém, nem sempre o que pensamos ser um problema, o é. Na verdade, pode ser um não-problema, e isso também precisa ser trabalhado na formação de professores.

Reconhecendo que as perguntas e problematizações são importantes para o ensino, o manual em questão parte de perguntas no início dos capítulos. Porém, muitas delas não são problemas reais para os estudantes, mas sim perguntas apenas na busca de definições:

- O que são paisagens?

- O que é geoconservação?

- Que tipos de forças existem?

Nesse caminho, a educação CTS poderia ser uma alternativa para entender os aspectos sociais e econômicos de construção da ciência e da tecnologia, os conflitos, a história, o uso de metodologias mais progressistas como a problematização, projetos temáticos com temas locais entre outros. No manual, é citado um tipo de educação CTSA (Ciência, Tecnologia, Sociedade e Ambiente), que possui um discurso muito colado a uma concepção de ciências neutra: aparece como quadros isolados somente no final dos capítulos com conteúdos pouco críticos. Por exemplo, "como apresentar um relatório de uma atividade laboratorial e/ou experimental", bem nos moldes do ensino de ciências tradicional.

No jogo entre a linguagem comum e a linguagem científica, trazemos como o uso da linguagem científica está ligado ao apagamento do autor e a algo de caráter impessoal e neutro. Geralmente os verbos são em terceira pessoa do singular (descobriu-se, observou-se, acredita-se), por exemplo: Os materiais comportam-se de modo diferente perante a corrente elétrica (COSTA; RODRIGUES; DIAS, 2011, p. 86). A linguagem impessoal produz sentidos que remetem à neutralidade, impessoalidade e a uma ciência que não tem história. Não há humanos, portanto não há erros. É como se o mundo falasse dele mesmo.

Nesse sentido, se o discurso científico produz efeitos de sentidos de neutralidade, a história da Ciência poderia contribuir para que os estudantes entendessem que a Ciência e os 
conceitos científicos têm história, pois se trata de uma construção humana. Porém, o manual em questão traz uma história da Ciência bastante linear, sem descontinuidades, sem relação alguma de seus pesquisadores e suas descobertas, com o contexto histórico-social da época, construída quase em sua totalidade por indivíduos isolados e por um acúmulo de fatos; é uma ciência ahistórica, europeia, branca, masculina.

As ideias de Quijano (2000) são importantes para entendermos as formas de colonialidade do saber que aqui se apresentam, ou seja, a dominação por meios não exclusivamente coercitivos, mas naturalizando o imaginário cultural europeu como forma única de relacionamento com a natureza, com o mundo social e com a própria subjetividade. Isso tudo contribui para que os sentidos construídos sobre esses conhecimentos sejam compreendidos por gerações como algo que carrega em si uma pretensão de objetividade, cientificidade e universalidade, acima do bem e do mal.

Nessa mesma direção e para encerrar as análises, trazemos a questão da ausência do diálogo de saberes. No manual do $7^{\circ}$ ano analisado, um capítulo diz respeito aos Sistemas, o qual tenta abarcar superficialmente oito deles - o Nervoso, o Endócrino, o Digestivo, o Respiratório, o Circulatório, o Excretor, o Imunitário e o Reprodutor. Além da superficialidade, destacamos aqui um exercício final que pergunta qual seria o tipo de medicina mais útil ao ser humano, e quais as contradições entre o saber científico e o saber local. Nessa atividade, as crianças devem se reunir em grupos de pesquisa, para posteriormente fazerem uma enquete acerca das vantagens e das desvantagens desses três temas, ou seja, desses três tipos de medicina (Figura 3).

Figura 3. Tipos de medicina a serem investigados, segundo o manual didático analisado

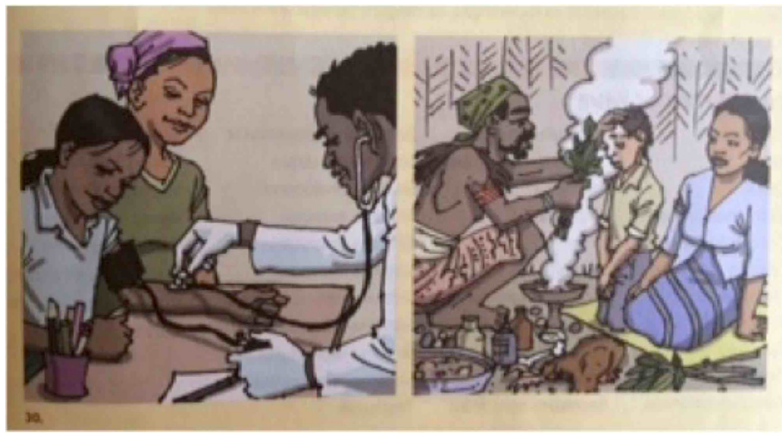

Grupos de pesquisa:

1. Medicina convencional;

2. Medicina tradicional baseada em evidências das experiências do dia a dia;

3. Medicina tradicional baseada na superstição, na magia e no obscurantismo.*

Fonte: Costa, Rodrigues e Dias (2011, p.175).

Note que há a palavra obscurantismo com um asterisco, e no glossário há a explicação do que significado desta palavra: “*obscurantismo: estado de quem vive na escuridão; na ignorância; doutrina dos que se opõem ao desenvolvimento da instrução e do progresso, pelo facto de os considerarem perigosos para a estabilidade social" (COSTA; RODRIGUES; DIAS, 2011, p. 175, grifos nossos). 
Na compreensão desse trecho do manual didático, salientamos três aspectos: a imagem, a separação entre as três medicinas e a definição de obscurantismo.

Em relação ao primeiro aspecto, apesar do livro falar em três medicinas, a imagem está dividida em apenas dois tipos de medicina que pode nos remeter: (a) a convencional e, (b) a tradicional baseada na superstição, na magia e no obscurantismo. Na primeira, podemos observar o rosto da paciente e de sua mãe com olhar confiante em um profissional da saúde, com o seu jaleco e luvas, além de um leve sorriso no rosto, aparentando transmitir segurança, ambos sentados em um consultório médico. Na outra imagem, um curandeiro com ervas, animais e outros produtos, sentados no chão, onde o paciente, com sua acompanhante, não parece muito bem, com expressão que parece assustada. É possível dizer que para um trabalho no qual se pesquisa o melhor tipo de medicina, as imagens já estão respondendo esse fato, trazendo um juízo de valor.

Em relação aos três tipos de medicina, os autores tentaram separar algo, ou seja, as duas medicinas tradicionais que a própria Organização Mundial de Saúde (OMS) admite como importante: "La medicina tradicional es una parte importante y con frecuencia subestimada de los servicios de salud. [...] Históricamente, la medicina tradicional se ha utilizado para mantener la salud, y prevenir y tratar enfermedades, en particular enfermedades crónicas" (ORGANIZACIÓN MUNDIAL DE LA SALUD, 2013, p. 10).

Até mesmo as crenças, nas quais o manual acaba por criticar subjetivamente, no terceiro tipo de Medicina, a OMS admite como sendo a soma de conhecimentos, habilidades e práticas baseadas em teoria, crenças e experiências indígenas de diferentes culturas, explicáveis ou não. Além disso, defendem seu uso, esclarecendo que é uma importante fonte econômica para o mercado (ORGANIZACIÓN MUNDIAL DE LA SALUD, 2013).

Para a sociedade timorense, cuja democracia é recente, e cujos pensamentos e saberes ancestrais estão tão presentes, consideramos que essas afirmações são impactantes. Ainda mais grave é quando pensamos nos interesses das indústrias farmacêuticas que chegam a patentear os princípios ativos de plantas selecionadas por conhecimentos milenares e consagrados pelas histórias dos povos indígenas, sem devolver aos povos o que lhes é direito. Nesse sentido, o texto do manual também induz a pensar que a prática da medicina convencional é recheada de verdades absolutas e não está associada a crenças. O que diriam quando em pesquisas na medicina convencional se conclui que o poder de orações ou efeito de medicamentos placebo podem contribuir na cura de doenças?

Quijano (2000) nos ajuda a entender os efeitos de colonialidade do saber que promove o silenciamento das muitas formas de conhecimento, próprias dos nativos de um lugar e que vão dando lugar a outras novas formas. Nelas, o que se pretende é uma perda de identidade cultural dos povos que acabam por ser inferiorizados, racionalizados, subalternizados, desumanizados, provocando baixa autoestima, dependência, falta de pertencimento. Ou seja, uma violência epistêmica com relação às outras formas de produção de conhecimentos, símbolos e modos de significar, a partir de uma eurocentrização cultural que se tornou aspiração, sedução e suposto caminho de acesso ao poder.

Todas essas questões fazem ainda mais sentido, quando lemos os filósofos clássicos, autores como Kant e Hume, entre vários outros, os quais até hoje embasam currículos e que acreditavam na superioridade civilizacional e cultural dos europeus. É o que podemos perceber nesse excerto abaixo do livro de Kant em Observações sobre o sentimento do belo e do sublime, de 1764, quando falava dos povos africanos: 
Os negros da África não possuem, por natureza, nenhum sentimento que se eleve acima do ridículo. O senhor Hume desafia qualquer um a citar um único exemplo em que um Negro tenha mostrado talentos, e afirma: dentre os milhões de pretos que foram deportados de seus países, não obstante muitos deles terem sido postos em liberdade, não se encontrou um único sequer que apresentasse algo grandioso na arte ou na ciência, ou em qualquer outra aptidão; já entre os brancos, constantemente arrojam-se aqueles que, saídos da plebe mais baixa, adquirem no mundo certo prestígio, por força de dons excelentes. (KANT, 1993, p. 75).

E, ainda acrescenta:

Tão essencial é a diferença entre essas duas raças humanas, que parece ser tão grande em relação às capacidades mentais quanto à diferença de cores. A religião do fetiche, tão difundida entre eles, talvez seja uma espécie de idolatria, que se aprofunda tanto no ridículo quanto parece possível à natureza humana. A pluma de um pássaro, o chifre de uma vaca, uma concha, ou qualquer outra coisa ordinária, tão logo seja consagrada por algumas palavras, tornam-se objeto de adoração e invocação nos esconjuros. Os negros são muito vaidosos, mas à sua própria maneira, e tão matraqueadores, que se deve dispersá-los a pauladas. (KANT, 1993, p. 76).

Nesse último exemplo do manual de ciências, pensamos que para ensinar numa perspectiva de alteridade, emancipação e não de subalternidade, é preciso focar numa perspectiva de diálogos de saberes. Nessa perspectiva, é preciso respeitar a cultura local, trazendo os saberes ancestrais, inclusive para identificar contribuições desses saberes para as outras sociedades, sem a hierarquia imposta pelo eurocentrismo.

Se pensarmos que são muitos Timores num só país, apesar de pequeno, há muito da cultura e da história ainda preservadas. As formas como lidam com os espíritos e a magia são muito particulares em cada aldeia, e isso aparece no manual didático como algo perigoso para a estabilidade social. Não se trata de excluir o conhecimento científico, mas de como no TL as crenças e os simbolismos estão muito ligados às noções de lugar e pertencimento. Fica problemático excluir todos esses saberes ancestrais, como o manual didático tenta impor algumas vezes. Este é composto por aspectos usados em sociedades ocidentalizadas e, principalmente, industrializadas, que na maioria das vezes não reflete a realidade do país. Então, há uma hierarquização do saber: o contexto é usado para ensinar a ciência ocidental e desvalorizar os saberes ancestrais.

Enfim, a atuação em contextos tão complexos, exige o estabelecimento de um diálogo de saberes, em contraposição a uma ideia de ciência neutra como um conhecimento superior a qualquer outro conhecimento. Como já dito, identificamos aqui a transnacionalização do currículo, ou seja, um deslocamento de conhecimentos pensados numa dada realidade para outras realidades socioculturais, desconsiderando os conhecimentos locais e, por consequência, tornando difícil os diálogos de saberes (DALE, 2004). Também, pode ser um modus operandi da colonialidade do saber/poder, como afirma Grosfoguel (2006, p. 73, grifos nossos): 
[...] la solución a las desigualdades globales requiere imaginar alternativas utópicas descoloniales globales anticapitalistas más allá de las formas de pensamiento binarias fundamentalistas eurocéntricas, nacionalistas y colonialistas así como las fundamentalistas del Tercer Mundo.

Enfim, essas questões devem ser tratadas como reflexos de um processo mais amplo, que partem de algumas ideias, como a globalização (e seus efeitos), a transnacionalização do currículo, promovendo uma educação assistencialista e o neocolonialismo, através da colonialidade do poder, saber, ser e viver. Como já dizia Apple (1999), na crítica à tradição seletiva dos conteúdos e ao enfoque de conteúdos com relevância social, somamos ao que Freire (1978) e Walsh (2009) vão chamar de conteúdos decolonizadores, que contêm outras histórias, conflitos e equívocos, problematizando conhecimentos dados como verdadeiros e neutros, para que possamos superar ações assistencialistas emancipatórias.

Por outro lado, não consideramos que se deve negar a importância da ciência e das formas de saberes ocidentais hegemônicas, e nem de cair em um relativismo cultural e epistêmico. Concordamos com Mignolo (2003) sobre valorizar as diversas histórias, saberes e epistemes locais que não são pensadas simplesmente como um resultado de diferenças culturais, mas sim, da diferença colonial, resultante da colonialidade do poder e do saber.

\section{Conclusões e estratégias de superação, para não jogar fora o bebê com a água do banho}

Considerando que os currículos construídos pelas cooperações internacionais não são e não devem ser pacotes lançados sobre as escolas, que irão consumi-los sem releituras, sem gestos de interpretação, partimos do pressuposto de que esses documentos sofrem várias interpretações num processo polissêmico, próprias do funcionamento da linguagem, pois esta não é transparente e nem de igual entendimento para todos. Se esses fenômenos da linguagem ocorrem em uma mesma língua, o que podemos propor num país que possui a Língua Portuguesa como língua de ensino, onde a maioria não é falante dessa língua? Nessa perspectiva, apesar dos documentos oficiais, em seu conjunto, aspirarem intervir no funcionamento dos demais contextos, essas orientações são interpretadas de diferentes maneiras nos contextos locais.

A explicitação, nesse artigo, de alguns discursos na educação científica timorense e seus efeitos, como a transnacionalização do currículo e os efeitos de colonialidade por meio dos livros didáticos, pode gerar dependência e subalternização, impondo verticalmente conhecimentos universais, neutros, ahistóricos, higienizados e sem diálogo de saberes.

Explicitar e desnaturalizar esses discursos é também uma forma de operar a decolonialidade do saber/poder/ser/viver, favorecendo construções de processos educacionais emancipatórios, influenciando nos efeitos de sentido sobre esses materiais, para que possam ser lidos criticamente pelos professores de Ciências, tanto no Timor-Leste quanto no Brasil, já que muitos problemas apontados aqui são recorrentes em nosso país.

Pensando na formação de professores sintonizados com as realidades socioculturais timorenses, apontamos que os temas que circulam nas escolas devem ser relacionados às situações-problema locais, discutidas e acordadas com os timorenses, e que precisam fazer sentido 
também dentro do ensino de Ciências, se pensarmos numa educação focada nas relações Ciência-Tecnologia-Sociedade. Nesse intuito, é preciso trabalhar temas que envolvam conflitos de interesses políticos, econômicos, sociais, ambientais e científicos, na formação de professores. Nesse caminho, entendo que os resultados dessa pesquisa podem contribuir para a formação de professores bem informados já em seus cursos iniciais. Desde 2013, ano em que foi constituído o primeiro grupo de pesquisa na Universidade Nacional de Timor Lorosa'e - o Grupo de Estudos em Pesquisa em Educação Científica e Tecnológica (GEECITE) ${ }^{6}$ - brasileiros e timorenses têm explicitado esses problemas e procurado ultrapassá-los. Esse repensar favorece discussões com os futuros professores de Ciências, sobre qual ciência e tecnologia ensinar, incentivando uma maior criticidade e contextualização, sem desprezar os manuais, os quais são tão raros em Timor-Leste (BARBOSA; CASSIANI, 2015).

A ideia não é jogar fora o bebê com a água do banho, ou seja, jogar fora os manuais em foco, mas apontar, a partir da noção de problema/não-problema/solução, que é possível explicitar/ construir com olhares mais críticos os manuais refletidos e elaborados com os timorenses, para as suas realidades, desafios e interesses.

A fim de estimular discussões, consideramos que algumas questões podem ser importantes para, de forma problematizadora, considerar os manuais como materiais de pesquisa: quais temas são relevantes para aquela comunidade? Como problematizar a colonialidade do saber e construir saberes situados? Como fazer uma discussão de forma problematizadora? O que é um problema? É possível ensinar sem a fragmentação existente no tradicional ensino de ciências? Como propor atividades nas quais os professores possam experimentar alguns processos investigativos de produção do conhecimento, além de seu conteúdo? O que os professores timorenses da educação? Como enxergam os pontos fracos e fortes da educação na atualidade?

Enfim, ao incorporar discussões nessas dimensões, muitas vezes silenciadas em debates da área da Educação em Ciências e associadas à compreensão dos processos que passou o Timor-Leste, é possível perceber a importância de uma educação mais crítica que possa contribuir para a sustentabilidade da paz (SILVA, 2012). Além disso, promover a segurança e estabilidade no país (FREIRE; LOPES, 2014). Portanto, este trabalho traz algumas provocações e tentativas de superações desses olhares.

\footnotetext{
${ }^{6}$ O GEECITE foi estruturado a partir de uma iniciativa dos timorenses para selecionar bolsistas do Programa de Pró-Mobilidade Internacional da CAPES e teve início em 2013. Trata-se do primeiro grupo de pesquisa da Universidade Nacional de Timor-Lorosa'e composto por estudantes de graduação das licenciaturas em ciências da natureza e professores.
} 


\section{Agradecimentos}

A autora agradece o apoio do Conselho Nacional de Desenvolvimento Científico e Tecnológico (CNPq) pela Bolsa de Pesquisa (PQ 1 D).

\section{Referências}

APPLE, M. Ideologia e currículo. Porto: Porto Editora,1999.

BARBOSA, A.; CASSIANI, S. Efeitos de colonialidade no currículo de ciências do ensino secundário em Timor-Leste. Revista Dynamis, Blumenau, v. 21, n. 1, p. 3-28, 2015.

CARTER, L. Challenges of postcolonialism to science education. Educational Philosophy and Theory, Abingdon, v. 38, n. 5, p. 677-692, 2006.

Thinking differently about cultural diversity: using postcolonial theory to (re)read science education. Science Education, Hoboken, v. 88, n. 6, p. 819-836, 2004.

CASSIANI, S.; BARBOSA, A. T. Efeitos da colonialidade no currículo do ensino secundário geral em Timor Leste: emancipação ou subalternidade? In: GUEDES, M. D. et al. (Org.). Professores sem fronteiras: pesquisas e práticas pedagógicas em Timor-Leste. Florianópolis: UFSC: NUP, 2015. p. 159-170.

CASSIANI, S.; LINSINGEN, I. Formação inicial de professores de ciências: perspectiva discursiva na educação CTS. Educar em Revista, Curitiba, Paraná, n. 34, p. 127-147, 2011.

CASSIANI, S. et al. Alguns estudos sobre a cooperação educacional em Timor Leste: foco na educação em ciências e tecnologias. Revista da SBEnBIO, Niterói, v. 9, p. 6385-6396, 2016.

CASTRO-GÓMEZ, S.; GROSFOGUEL, R. E1 giro decolonial: reflexiones para una diversidad epistémica más allá del capitalismo global. Bogotá: Panamericana Formas e Impresos, 2007.

COSTA, I. A.; RODRIGUES, M. M. R. D.; DIAS, F. M. L. Aprender ciências: ciências físico-naturais. Porto: Porto Editora, 2011.

DALE, R. Globalização e educação: demonstrando a existência de uma "cultura educacional mundial comum" ou localizando uma "agenda globalmente estruturada para a educação?" Educação e Sociedade, Campinas, v. 25, n. 87, p. 423-460, 2004.

FREIRE, P. Cartas à Guiné-Bissau: registros de uma experiência em processo. 2. ed. Rio de Janeiro: Paz e Terra, 1978.

Extensão ou comunicação? Rio de Janeiro: Paz e Terra, 1985.

FREIRE, R.; LOPES, P. D. Consolidação da paz numa perspetiva crítica: o caso de TimorLeste. Revista Crítica de Ciências Sociais, Coimbra, n. 104, p. 5-20, 2014.

GABRIELSON, C. Ensiklopedia multimedia: siensia no matematika iha ita nia moris loroloron. 2009. Disponível em: < https://pt.scribd.com/document/36715467/East-TimorEncyclopedia-Selections-in-English>. Acesso em: 2 fev. 2018. 
Reflexões sobre os efeitos da transnacionalização de currículos ...

GONÇALVES, M. R. A língua portuguesa e o conflito intergeracional em Timor-Leste. In: TEIXEIRA, R. et al. (Ed.). In: SIMELP, 3., 2012, A formação de novas gerações de falantes de português no mundo. Macau: Universidade de Macau, 2012.

GROSFOGUEL, R. La descolonización de la economia politica y los estudios postcoloniales: transmodernidad, pensamiento fronterizo y colonialidad global. Notas de Población, Santiago de Chile, n. 80, p. 53-74, 2006. Disponível em: < http://biblioteca. clacso.edu.ar/Panama/cela/20120718102251/descolonizacion.pdf>. Acesso em: 2 fev. 2018.

KANT, E. Observações sobre o sentimento do belo e do sublime. Campinas: Papirus, 1993.

MIGNOLO, W. D. Histórias locais: projetos globais. Belo Horizonte: Editora da UFMG, 2003.

ORGANIZACIÓN MUNDIAL DE LA SALUD. Estrategia de la OMS sobre medicina tradicional: 2014-2023. Ginebra, 2013. Disponível em: <http://apps.who.int/medicinedocs/ documents/s21201es/s21201es.pdf>. Acesso em: 2 fev. 2018.

ORLANDI, E. P. As formas do silêncio: no movimento dos sentidos. 3. ed. Campinas: Ed. Unicamp, 1995. 1996.

Interpretação: autoria, leitura e efeitos do trabalho simbólico. Petrópolis: Vozes,

Língua brasileira e outras histórias: discurso sobre a língua e ensino no Brasil. Campinas: Editora RG, 2009.

ORTIZ, R. Mundialização e cultura. 2. ed. São Paulo: Brasiliense, 1994.

PACHECO, J. A. et al. Plano curricular do $3^{\circ}$ ciclo do ensino básico e estratégia de implementação. Braga: Universidade do Minho, 2009. (Projecto de desenvolvimento do currículo do $3^{\circ}$ ciclo da educação básica em Timor-Leste). Disponível em: < https: / tinyurl. com/yd4krk3w>. Acesso em: 2 fev. 2018.

PECCHEUX, M. O discurso. Campinas: Pontes, 1993.

PEREIRA, P. B. O programa de qualificação de docentes e ensino de língua portuguesa no Timor-Leste (PQLP): um olhar para o ensino de ciências naturais. 2014. Tese (doutorado) - Universidade Federal de Santa Catarina, Florianópolis, 2014.

PEREIRA, P. B.; CASSIANI, S.; LINSINGEN, I. v. International educational cooperation, coloniality and emancipation: the program teacher qualification and Portuguese language teaching in East Timor and the teacher education. Revista Brasileira de Pós-Graduação, Brasília, v. 12, n. 27, p. 193-218, 2015.

QUIJANO, A. Colonialidad del poder, eurocentrismo y América Latina. In: LANDER, L. (Org.). La colonialidad del saber: eurocentrismo y ciencias sociales: perspectivas latinoamericanas. Buenos Aires: CLACSO, 2000. p. 122-146. 
RAMOS, A. M.; TELES, F. Memória das políticas educativas em Timor-Leste: consolidação de um sistema (2007-2012). Aveiro: Universidade de Aveiro, 2012.

SANTOS, B. S. Descolonizar el saber, reinventar el poder. Montevideo: Trice, 2010.

SANTOS, B. S.; MENESES, M. P. (Org.). Epistemologias do sul. Coimbra: G. C. Gráfica, 2013.

SILVA, A. B. Modelo de letramento da pedagogia Maubere. 2012. Tese (Doutorado) Instituto de Estudos de Paz e Conflito, Universidade Nacional de Timor Leste, Dili, 2012.

SOUZA, M. I. S.; ALVES, R. C. Transnacionalização da educação?: a ajuda externa à educação em Timor Leste e o papel da CAPES. In: SIMPÓSIO INTERNACIONAL O ESTADO E AS POLÍTICAS EDUCACIONAIS NO TEMPO PRESENTE, 4., 2008, Uberlândia. Anais... Uberlândia : UFU, 2008.

TIMOR-LESTE. Ministério da Educação. Plano estratégico nacional da educação 20112030. Dili, 2011. Disponível em: <https://tinyurl.com/y9es6qs8>. Acesso em: 2 fev. 2018.

WALSH, C. Interculturalidad crítica y pedagogía de-colonial: apuestas (des)de el in-surgir, re-existir y re-vivir. In: MEDINA, P. Educación intercultural en América Latina: memorias, horizontes históricos y diyuntivas políticas. México: Plaza y Valdés, 2009. p. 25-42.

Artigo recebido em 23/06/2017. Aceito em 19/08/2017.

Endereço para contato: UFSC, Centro de Ciências da Educação,

Departamento de Metodologia de Ensino, sala 212, Campus

Universitário, Flotianópolis, SC, 88040-900, Brasil. 